HELMINTHOLOGIA, 58, 4: 339 - 345, 2021

\title{
Excretion of dietary zinc in mammals (rats) fed overdoses of zinc lactate and infected with tapeworms
}

\author{
V. SLOUP*, I. JANKOVSKÁ ${ }^{1}$, J. SZÁKOVÁ2, V. KAREŠOVÁ ${ }^{1}$, S. LANKOVÁ1, S. SLOUP ${ }^{1}$, I. LANGROVÁ1
}

${ }^{1}$ Department of Zoology and Fisheries, Faculty of Agrobiology, Food and Natural Resources, Czech University of Life Sciences, Kamýcká 957, 165 21, Prague 6, Suchdol, Czech Republic, "E-mail: vsloup@af.czu.cz; 'Department of Agroenvironmental Chemistry and Plant Nutrition, Faculty of Agrobiology, Food and Natural Resources, Czech University of Life Sciences, Kamýcká 957, 165 21, Prague 6, Suchdol, Czech Republic

Article info

Received January 19, 2021

Accepted July 3, 2021

\section{Summary}

Tapeworms parasitize at sites that are important for the management of micronutrients, including zinc. Therefore, it has been hypothesized that tapeworms will significantly affect the excretion of zinc in the feces of a host. The aim of this work was to evaluate the effects that tapeworms have on the excretion of zinc in the feces of the host. Rats were divided into 4 groups: groups 0T and MT (infected with Hymenolepis diminuta (Rudolphi, 1819)) and groups 00 and M0 (uninfected). The experimental groups (M0 and MT) were fed a standard rodent compound feed (ST-1) with added zinc lactate; the daily zinc intake was $20.5 \mathrm{mg}$. The control groups (00 and OT) were fed only ST-1 with $1.75 \mathrm{mg}$ of added $\mathrm{Zn}$ per day. For six weeks, the amount of consumed feed was recorded and fecal samples were taken. The samples were then analyzed by optical emission spectrometry (ICP-OES), and levels of excreted zinc were subsequently calculated as a percentage. The most significant difference in zinc excretion levels between the experimental groups was observed in the third week, when rats infected with tapeworms (MT) excreted substantially lower levels of zinc than did uninfected rats (M0). This difference amounted to $28.36 \%(p<0.01)$. In the control groups, tapeworms affected the excretion of zinc in the feces to a lesser extent, and the most substantial difference in zinc levels was seen in the fifth week (8.46\%). However, there was no significant difference in zinc excretion levels between the control groups during any of the monitored weeks. Tapeworms in the host affect levels of zinc excreted in the feces. However, this is dependent on the amount or form of zinc ingested.

Keywords: zinc; excretion; fecal; tapeworm; rat; supplement

\section{Introduction}

Zinc is present in all biological systems and, owing to its versatile physicochemical properties, performs various functions in the body. Zinc is involved in the metabolism of insulin (Khoobbakht et al., 2020), carbohydrates, lipids and proteins. Zinc forms part of the digestive enzyme, and it is an important antioxidant which removes free radicals and protects cell membranes against lipid peroxidation. It significantly contributes to the growth and develop- ment of the individual as well as the proper functioning of the immune and reproductive systems (Williams, 2012; Gonçalves-Neto et al., 2011). Zinc is released from food in the form of free ions. This occurs primarily in the distal duodenum and proximal jejunum. Approximately $60 \%$ of absorption occurs in the duodenum, $30 \%$ in the ileum, $7 \%$ in the jejunum, and roughly $3 \%$ in the appendix and colon (Hotz et al., 2004). Zinc is absorbed by enterocytes through the basolateral membrane and then passes into the portal circulation. The portal system directs the zinc to the liver, from where it

\footnotetext{
$\overline{\text { * - corresponding author }}$
} 
Table 1. Zinc contents in feed.

\begin{tabular}{ccccc}
\hline Experimental group & Number of animals & Infection tapeworm & Zinc dose $(\mathrm{mg} / 25 \mathrm{~g}$ food $)$ & Zinc dose/week $(\mathrm{mg})$ \\
\hline O0 & 6 & - & 1.75 & 10.5 \\
OT & 6 & + & 1.75 & 10.5 \\
MO & 6 & - & 20.5 & 123 \\
MT & 6 & + & 20.5 & 123 \\
\hline
\end{tabular}

is released into the bloodstream, eventually reaching other tissues (Hotz et al., 2004). However, if zinc is ingested in high amounts, it is absorbed at the expense of other trace elements, and this may be expressed as a reduction in their uptake. This leads to a disruption of the metabolic processes that are dependent on these elements (Ferguson et al., 1995).

Zinc excretion takes place mainly through feces, which contains unabsorbed zinc from food consumption, zinc present in intestinal epithelial cells, as well as endogenous zinc, which is excreted into the intestine by the gallbladder, pancreas, and gastroduodenal secretions (Erdman et al., 2012). Approximately 70 to $80 \%$ of ingested zinc is excreted in this way (Davies \& Nightingale, 1975). There is also evidence that zinc exerts a negative effect on ecosystems, basic soil functions and species diversity among microorganisms. This can, in turn, negatively affect the conversion of nutrients in the soil. In order to ensure protection of the environment and public health, a number of steps have been taken to reduce heavy metal emissions in recent years. However, such steps have not been applied to zinc. Zinc continues to be a common additive in compound feed. For example, zinc is given to newly weaned piglets in order to reduce the incidence of diarrhea (Jensen-Waern et al., 1998) and improve both growth parameters and daily weight gain. However, such use of zinc leads to its accumulation in the environment and also to the development of bacterial resistance in LA-MRSA (livestock associated methicillin resistant Staphylococcus aureus (Rosenbach, 1884)). In Denmark, an increase in soil zinc concentrations of more than $45 \%$ was recorded between 1998 and 2014. Based on those results, European agencies (EMA, EFSA) are reviewing the current permitted levels of zinc in compound feed (e.g. Directive 2016/1095) (Jensen et al., 2018).

$\mathrm{Zn}$ in animals is taken up orally and subsequently absorbed and excreted mainly by the digestive tract. Since gastrointestinal helminths (including tapeworms) are present in the digestive tract, they can influence zinc metabolism significantly. According to many authors, tapeworms of the genus Hymenolepis can accumulate significant amounts of metal ions taken up by the host (Sures et al., 2002; Jankovská et al., 2018).

Our study, therefore, focused on comparing the levels of zinc ingested and excreted by rats infected with tapeworms to those ingested and secreted by uninfected rats. In addition to being given the standard dose of zinc, some rats received a zinc lactate additive. Thus, it has been hypothesized that tapeworms will significantly affect the excretion of zinc in the feces of a host.

\section{Material and Methodology}

\section{Maintenance of experimental animals}

Twenty-four male Wistar rats (Rattus norvegicus domestica) were used in the study. The average initial weight of each rat was $150 \mathrm{~g}$. Each animal was placed in its own metabolic cage for the duration of the experiment. The room housing the cages was equipped with air-conditioning. A constant temperature $\left(22-24^{\circ} \mathrm{C}\right)$ and relative humidity level (approx. $70 \%$ ) were maintained at a constant day/ night cycle (08:00 am - 08:00 pm). The animals had access to water ad libitum during the experiment. They were fed a standard mixture for rodents (ST-1 by Velaz, Prague, Czech Republic, see Table 2).

\section{Rat tapeworm infection}

During acclimatization, some rats were infected with the tapeworm H. diminuta. Tapeworm intermediate hosts were used for infection, namely beetles of the species Tribolium confusum (Jacquelin du Val, 1868). The beetles were infected by consuming the tapeworm eggs. Tapeworm larvae (cysticercoids) developed in beetles in an incubator over 12 days at $29^{\circ} \mathrm{C}$. After this time, the cysticercoides were extracted from the beetles and administered to rats orally

Table 2. Composition of ST-1 (commercially available from Velaz Ltd. CR).

\begin{tabular}{ll}
\hline Moisture (\%) & 12.5 \\
Nitrogen compounds (\%) & 24 \\
Fiber (\%) & 4.4 \\
Lipids (\%) & 3.4 \\
Ash (\%) & 6.8 \\
Lysin (mg/kg) & 14000 \\
Methionine (mg/kg) & 4800 \\
Ca (mg/kg) & 11000 \\
P (mg/kg) & 7200 \\
Na (mg/kg) & 1800 \\
Cu (mg/kg) & 20 \\
Zn $(\mathrm{mg} / \mathrm{kg})$ & 70 \\
Se $(\mathrm{mg} / \mathrm{kg})$ & 0.38 \\
\hline
\end{tabular}


using pipettes filled with a sucrose solution (three larvae per rat). Success of infection was determined by a coprological examination carried 5 weeks after infection.

\section{Experimental Design}

After acclimatization, the rats were divided into four groups (see Table 1). Each rat received $25 \mathrm{~g}$ of food per day for every day of the experiment ( 6 weeks), with the exception of Fridays, when they were given $50 \mathrm{~g}$ and then received another dose of food, again on Monday, again $25 \mathrm{~g}$. Group 00 (no tapeworm infection) rats were fed a standard rodent compound feed (ST-1) during the experiment. The daily feed ration $(25 \mathrm{~g})$ contained $1.75 \mathrm{mg}$ of $\mathrm{Zn}$. Group $0 \mathrm{~T}$ rats were fed the same mixture as those of group 00 , but they were infected with $H$. diminuta. Group M0 (no tapeworm infection) rats were fed ST-1 with zinc lactate (p.a. grade, Lachema, Brno, Czech Republic). The daily ration $(25 \mathrm{~g})$ contained $20.5 \mathrm{mg}$ of $\mathrm{Zn}$. Group MT rats (tapeworm infected) were also fed ST-1 with added zinc lactate. The amount of ingested food was recorded on a daily basis. Fecal samples were weighed, described and stored in a refrigerator until they were tested in a laboratory for the presence of $z i n c$. The levels of $Z n$ excreted in the feces were calculated on the basis of data regarding the amounts of ingested and excreted zinc.

\section{Analytical procedures}

All samples were placed into plastic boxes and stored at $-20^{\circ} \mathrm{C}$ until chemical analysis. Frozen samples were lyophilized and ground into a fine powder (LYOVAC GT 2: LEY-BOLD-HERAEUS, GmbH,
Germany). The powder was then added to a mixture of hydrogen peroxide $(35 \%)$ and nitric acid $(65 \%)$. Finally, the entire mixture underwent microwave digestion.

Concentrations of $\mathrm{Cd}$ in the digests were measured by Electrothermal Atomic Absorption Spectrometry using a Varian AA $280 Z$ spectrometer (Varian, Australia) with a graphite tube atomizer GTA 120 and a PSD 120 programmable sample dispenser. Zinc concentrations in digests were determined by optical emission spectroscopy with inductively coupled plasma (ICP-OES) and axial plasma configuration using a Varian VistaPro, equipped with an SPS-5 autosampler (Australia). Measurement conditions for all lines were as follows: $1.2 \mathrm{~kW}$ (power); $15.0 \mathrm{~L}$ min-1 (plasma flow); $0.75 \mathrm{~L}$ min-1 (auxillary flow); and $0.9 \mathrm{~L}$ min-1 (nebulizer flow.)

The quality of analytical data was assessed by simultaneous analysis of certified reference material CRM 12-02-01 (Bovine Liver; $4 \%$ of samples). Analytical data obtained for all elements were within the confidence interval given by the producer. The background of the trace element laboratory was monitored by an analysis of $15 \%$ blanks prepared under the same conditions (without samples), and experimental data were corrected by mean concentration of the elements in blanks and compared with detection limits (mean $\pm 3 \mathrm{SD}$ of blanks) which were $7.5 \mathrm{ng} \mathrm{mL}-1$ for $\mathrm{Zn}$.

\section{Statistical analysis}

For each sample, differences between $\mathrm{Zn}$ intake and excretion levels were calculated and expressed as a percentage. Statistica 10 software (Statsoft, USA) was used for all computations and statis-

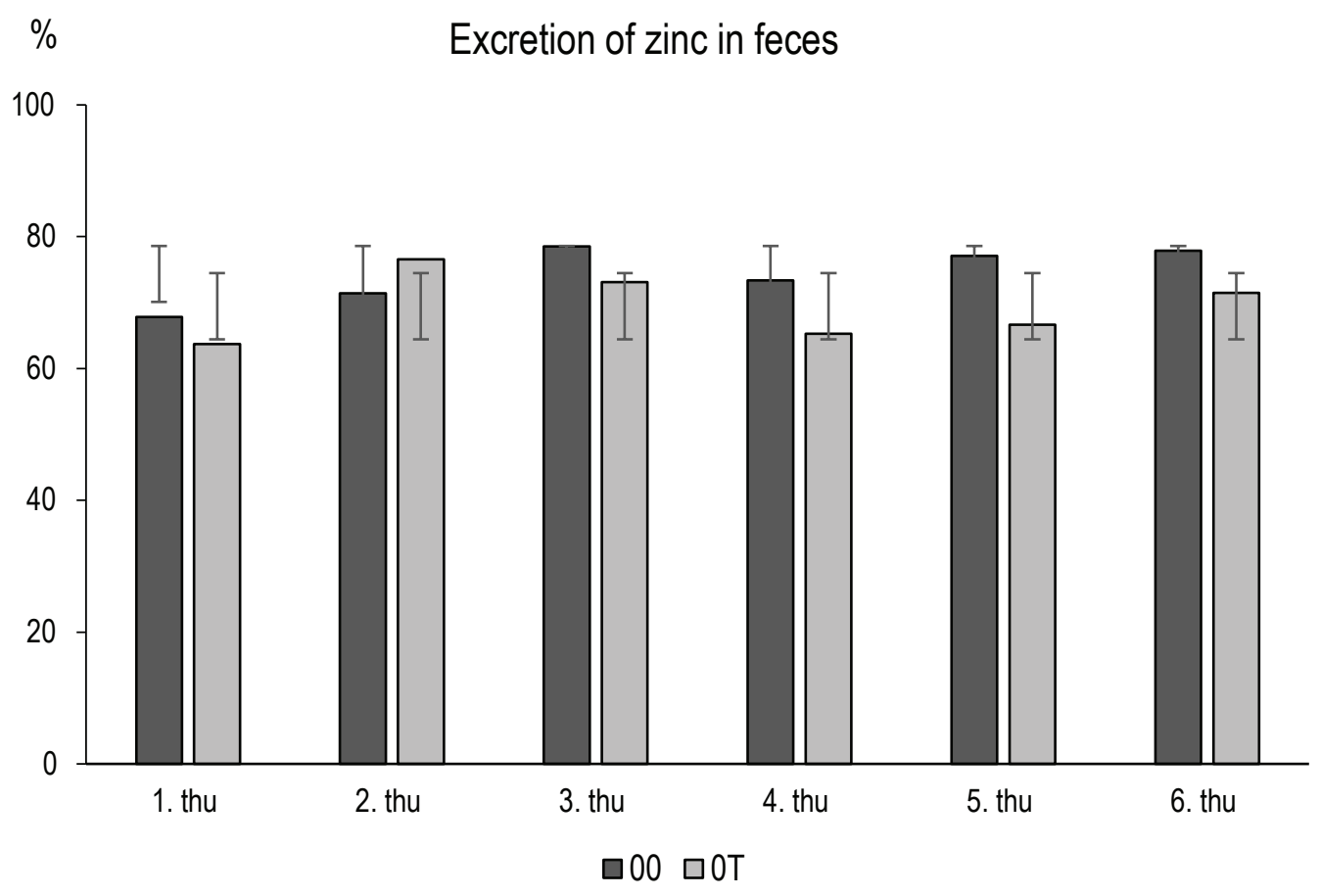

Fig. 1. A comparison of $\mathrm{Zn}$ excretion rates (\%) in the feces of uninfected control rats $(00)$ and those of control rats (OT) infected with tapeworms (Hymenolepis diminuta). thu, Thursday (samples were taken every Thursday) 
tical analyses. The normality of data was tested separately using a Shapiro-Wilk test. We then used a nonparametric Mann-Whitney $U$ test to evaluate the proposed hypothesis. Our hypothesis produced a $p$-value $<0.05$ (marked with an asterisk in Figure 2) regarding the statistically significant influence of zinc in rat feed. A p-value $<0.01$ was applied to highlight statistically significant differences, which were indicated with two asterisks in Figure 2.

\section{Ethical Approval and/or Informed Consent}

The authors confirm that the ethical policies of the journal, as noted on the journal's author guidelines page, have been adhered to and the appropriate ethical review committee approval has been received. The authors confirm that they have followed EU standards for the protection of animals used for scientific purposes [and feed legislation, if appropriate]. All experiments with laboratory animals were conducted in compliance with the current laws of the Czech Republic, Act No. 246/1992 coll. on the protection of animals against cruelty and EC Directive 86/609 EEC.The study was approved by the ethic committee of Czech University of Life Sciences Prague.

\section{Results}

Tapeworms have generally been shown to reduce the amount of zinc in the feces of a host. However, infected rats in the control groups (00 and $0 \mathrm{~T}$ ) excreted more $\mathrm{Zn}$ than did rats without tapeworms (6.3\%); this was the case even during the second week of the study. For the remaining weeks, rats in group 0T excreted less $\mathrm{Zn}$ in feces than did rats in group 00 (the most dramatic difference was observed in the fifth week: $8.5 \%$ ); however, differences between these two groups were not considered significant (Fig. 1).

When comparing the groups that are provided with high amounts of zinc in their feed (M0; MT), it is evident that the tapeworm does have an effect on the excretion of this metal in the feces. Throughout the entire six weeks of study, rats of the MT group excreted less zinc in the feces than did uninfected rats (MO). In the first week, only insignificant differences between the two groups were observed. During the next five weeks, however, differences in $\mathrm{Zn}$ levels between the two groups were determined to be statistically significant. These differences were evaluated as more significant $(p<0.01)$ in the $3 r d(28.4 \%)$, 5th $(27 \%)$, and 6th $(24.9 \%)$ week (Fig. 2).

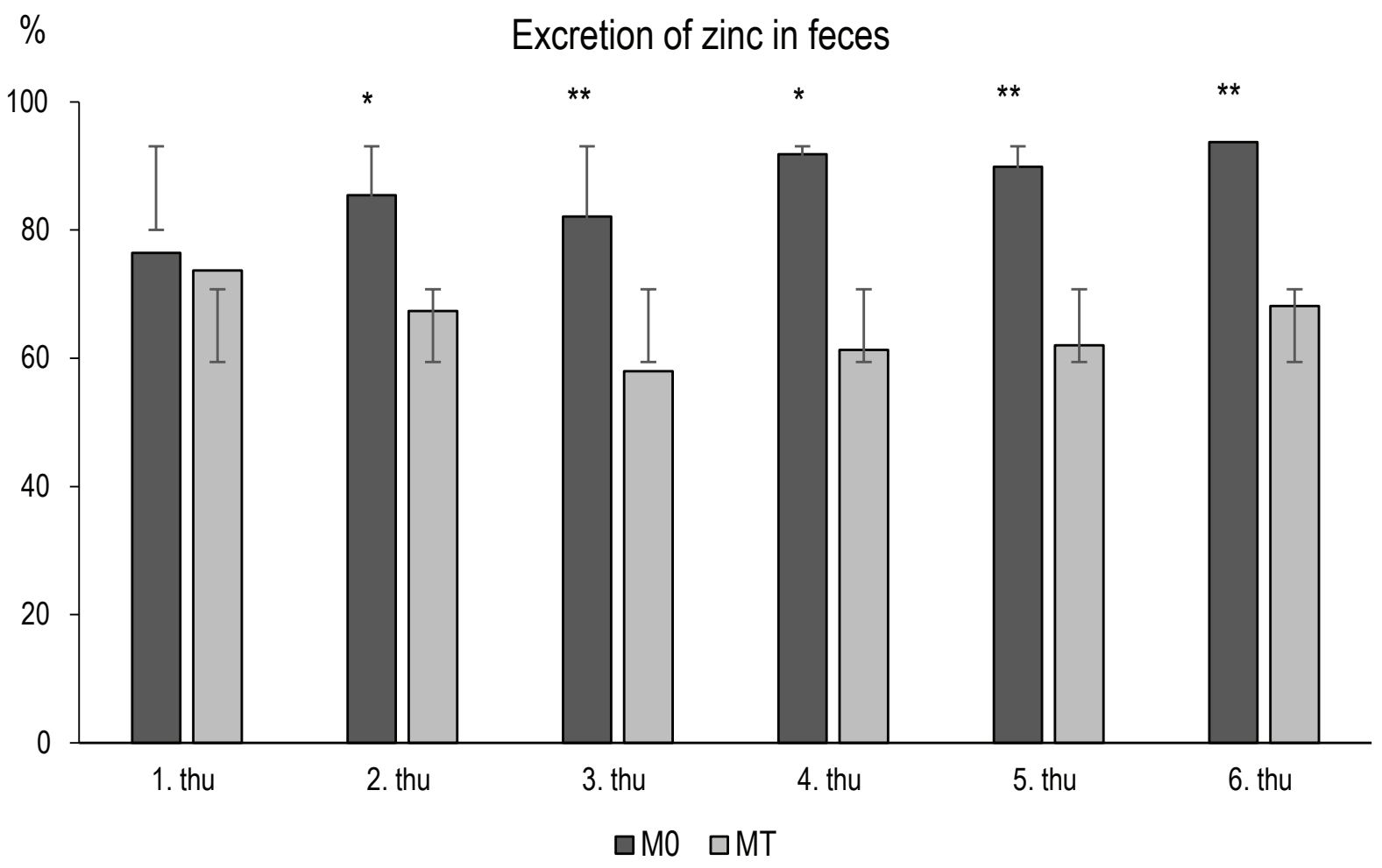

Fig. 2. A comparison between $\mathrm{Zn}$ excretion rates (\%) in the feces of rats from group M0 (uninfected and fed Zinc lactate) and those of rats from group PT (tapeworm-infected and fed Zinc lactate).

${ }^{*}$ Statistically significant difference between groups $\mathrm{M0}$ a MT, $\mathrm{p}<0.05$;

${ }^{* *}$ Statistically significant difference between groups $\mathrm{M} 0$ a MT, $p<0.01$;

thu, Thursday (samples were taken every Thursday) 
Table 3. Zinc dosages and levels of Zn excreted in feces (mg) over a 6-week period.

\begin{tabular}{cccc}
\hline Experimental group & Zinc intake (mg/day) & Faecal excretion zinc (mg/day) & Faecal excretion zinc (\%) \\
\hline O0 & $1.75 \pm 0.13$ & $1.22 \pm 0.18$ & 73.67 \\
OT & $1.71 \pm 0.16$ & $1.19 \pm 0.19$ & 70.19 \\
MO & $20.25 \pm 1.12$ & $17.64 \pm 2.78$ & 87.2 \\
MT & $19.23 \pm 1.75$ & $12.90 \pm 1.79$ & 64.84 \\
\hline
\end{tabular}

Values expressed as the median \pm standard deviation in the group

The values of fecal zinc excretion for the entire duration of the experiment indicate that the MT group excreted over $20 \%$ less zinc than did the M0 group. Differences in $\mathrm{Zn}$ levels between groups 00 and $\mathrm{OT}$ were not considered significant; rats with tapeworms excreted less zinc in feces than did rats without tapeworms. The MO group excreted the excreted the highest levels of zinc of all groups, while the MT group excreted the lowest levels. Thus, the difference in zinc levels between groups M0 and MT was significantly greater $(p<0.01)$ than it was between groups 00 and 0T. Tapeworm infection had the strongest effect on zinc levels in the feces of rats fed high doses of zinc (Table 3).

\section{Discussion}

Zinc is an element that is essential for the proper functioning of animal metabolism, but it can also be toxic in high doses. Insufficient nutritional intake of zinc is relatively common in some areas, so dietary supplements, among them zinc, are used to complement the diet. These supplements contain various zinc compounds, some of which are well absorbed, while others are not. In our study, we chose zinc lactate as a dietary zinc supplement. Hotz et al. (2004), state that in order to focus future research on the intake and excretion of zinc, there is a need to clarify the role gastrointestinal helminths play in these processes. This was the main objective of our study.

Gastrointestinal parasites come into contact with ingested food before it is absorbed by the host's digestive tract, and this has an effect on the amount of nutrients available to the host. Krebs (2000) states that in humans and animals, two factors are most important for maintaining zinc homeostasis - endogenous intestinal excretion and the amount of zinc absorbed by the intestine.

According to Hall et al. (2008), tapeworms impair the absorption of nutrients, especially in the final portion of the ileum, of the ileum, and this impairment can lead to anemia. In addition, according to Hotz et al. (2004), approximately $30 \%$ of zinc is absorbed in the ileum, and Johnson (1989) reported levels as high as $60 \%$. Wada et al. (1985) report that approximately $53 \%$ and $49 \%$ of zinc is absorbed at dietary doses of $16.5 \mathrm{mg} /$ day and $5.5 \mathrm{mg} /$ day, respectively. In contrast, Jackson et al. (1984) state that when dietary zinc is increased, the levels of absorbed zinc decrease. When levels of dietary zinc were doubled, the absorption rate was $45 \%$ for the first 4 days and decreased to $32 \%$ during the following 4-day period. Another study also proves the extraordinary ability of the body to regulate zinc intake. King et al. (2000) report that the body absorbs up to $100 \%$ of ingested zinc when a diet is lacking in this metal. When rats were fed $0.5 \mathrm{mg}$ of $\mathrm{Zn}$ per day, the absorption rate decreased to $55 \%$ (King et al., 2000).

In our experiment, control rats from groups $0 \mathrm{~T}$ and 00 received an average of $1.71 \mathrm{mg}$ and $1.75 \mathrm{mg}$ of $\mathrm{Zn}$ per day, respectively. Groups $0 \mathrm{~T}$ and 00 excreted $70 \%$ and $74 \%$ of ingested zinc, respectively. Rats in experimental group M0 excreted, on average, the highest levels of ingested zinc from all the groups, namely $87 \%$ (Table 3); the highest levels (94\%) were eliminated in the final week. This confirms that the organism responds to a higher content of zinc in the diet by excreting higher amounts in the feces. The study of Cadkova et al. (2013) demonstrates how the type of ingested $\mathrm{Zn}$ can play an important role in the absorption process. The authors administered lead to rats in two different forms - lead acetate and phytobound $\mathrm{Pb}$ (Pistia stratiotes (Linné, 1753)). Their results show that $53 \%$ of the ingested lead was excreted in the feces within 24 hours of exposure. In our study, from $65 \%$ (MT group) to $87 \%$ (M0 group) of ingested zinc was excreted 24 hours after exposure.

Cadkova et al. (2013) also determined that lead acetate was excreted in greater amounts than lead in hyperaccumulator.

Although zinc was not evaluated in the study of Cadkova et al. (2013), we can assume, due to their similar physicochemical properties, that zinc, cadmium and lead (Das et al., 1997; Chaney, 2010), behave in a similar manner. For example, Decker et al. (1957) orally administered $2 \mathrm{mg}$ of cadmium to rats. They found that $90 \%$ of the administered dose was excreted in the feces. This amount is similar to the values of zinc excreted by feces. According to a study by Horakova et al. (2017), zinc, cadmium and lead are concentrated in the same areas of the tapeworm, namely the immature strobils, so it can be assumed that these metals are indistinguishable from one another for the tapeworm. In our experiment, zinc lactate was used to increase zinc content in feed. Zinc is a compound of metal and organic acid, such as lead acetate.

Based on the results of Cadkova et al. (2013), we can expect the amount of zinc excreted in the feces to be higher after the intake of zinc lactate than it would be after the intake of phytobound $\mathrm{Zn}$.

This is confirmed by a comparison with the results of one of our previous publications (Sloup et al., 2018), where we evaluated how tapeworms affect the excretion of zinc and cadmium in the 
feces of rats fed Arabidopsis halleri (Hayek, 1908). The results indicated that the uninfected group that were fed $A$. halleri excreted $78 \%$ and $70 \%$ of zinc and cadmium in the feces, respectively. The group infected with tapeworms and fed $A$. halleri excreted $76 \%$ and $61 \%$ of zinc and cadmium in the feces, respectively. In our new study, rats from the M0 and MT groups excreted $87 \%$ and $65 \%$ of zinc in their feces respectively (Table 3). The levels of zinc excreted in the feces from ingested zinc lactate were actually higher than those from zinc ingested in the form of phytobound $\mathrm{Zn}$. Isaure et al. (2015) state that zinc, cadmium and lead are also bound as a metal-organic acid complex in hyperaccumulators, including $P$. stratiotes and $A$. halleri.

This finding is unexpected, as the amount of zinc absorbed and excreted can be affected by phytic acid, which is considered an antinutritional agent that reduces the utilization of certain nutrients, including zinc (House et al., 1982). Moreover, according to Milne et al. (1984), phytic acid significantly reduces the absorption of Zn. In contrast, the bioavailability of zinc from zinc lactate is thought to be very high, even higher than that of zinc gluconate, which is very well-absorbed (Shengkui et al., 1994).

The MT group excreted $65 \%$ of ingested zinc, while the infected group that were fed $A$. halleri excreted $76 \%$ of ingested zinc (Sloup et al., 2018). This can be attributed to the ability of the tapeworm to absorb more zinc from a diet rich in zinc lactate, which has a high bioavailability, than it could from a diet with added $A$. halleri. However, it is also possible that the tapeworms of $A$. halleri received less zinc because in addition to $\mathrm{Zn}$, the plants contained hazardous metals, namely cadmium, which the zinc lactate diet did not. Another reason could be tapeworm intoxication in the intestine of rats fed A. halleri. According to Scott and Koski (2000), a high zinc content has a negative effect on tapeworms. A relatively high intake of cadmium and zinc could also lead to a poisoning of the tapeworms in cases where rats are fed a diet with added A. halleri. This in turn could result in tapeworms with smaller dimensions. These smaller tapeworms would accumulate less zinc than would tapeworms that were exposed to high levels of zinc exclusively through a diet fortified with zinc lactate.

\section{Conclusion}

Although the entire complex of processes that ultimately determine how much zinc will be absorbed, excreted, and ultimately accumulated in an animal depends on a number of factors, tapeworms represent an integral and important part of such processes. The amount of metal in the diet is one of the most important factors for homeostasis. However, the type of ingested zinc, food composition and the quantity of other nutrients are also vital. This is evident from our results, which indicated that tapeworm presence had a significant effect on zinc excretion in rats fed high doses of zinc (M0 and MT groups) that was not evident in rats fed a standard diet containing normal amounts of the metal (groups 00 and OT). Our hypothesis was thus partially confirmed.

\section{Conflict of Interest}

The authors declare no conflict of interest.

\section{Acknowledgements}

The authors gratefully acknowledge Mr. Brian Kavalir (Ontario, Canada) for his proofreading services.

This research was performed within the Centre for Infectious Animal Diseases initiative, Centre for Infectious Animal Diseases, Faculty of Agrobiology, Food a Natural Resources, Czech University of Life Sciences Prague.

\section{Funding}

The authors declare no specific funding for this work.

\section{References}

Chaney, R.L. (2010): Trace elements in soils. In Chaney, R.L. (Eds) Cadmium and zinc, School of Geography, Geology and the Environment. Kingston University, London, pp. 409 - 439 DOI: 10.1002/9781444319477.ch17

Čadková, Z., Száková, J., Miholová, D., Válek, P., Pacáková, Z., VAdLeJCH, J., LANGRová, I., JankovsKÁ, I. (2013): Faecal excretion dynamic during subacute oral exposure to different $\mathrm{Pb}$ species in Rattus norvegicus. Biol Trace Elem Res, 152: 225 - 232. DOI: 10.1007/s12011-013-9609-8

Das, P., Samantaray, S., Rout, G.R. (1997): Studies on cadmium toxicity in plants: a review. Environ Pollut, 98: $29-36$. DOI: 10.1016/S0269-7491(97)00110-3

DaVies, N.T., NIGHTINGALE, R. (1975): The effects of phytate on intestinal absorption and secretion of zinc, and whole-body retention of $\mathrm{Zn}$, copper, iron and manganese in rats. Br J Nutr, 34: $243-258$. DOI: 10.1017/S0007114575000293

DeCKer, C.F., Byerrum, R.U., Hoppert, C.A. (1957): A study of the distribution and retention of cadmium-115 in the albino rat. Arch Biochem Biophys, 66: 140 - 145. DOI: 10.1016/00039861(57)90544-1

ERdman, J.W., MacDonald, I.A., ZeISeL, S.H. (2012): Present knowledge in nutrition. 10 ${ }^{\text {nd }}$ Edition, Wiley-Blackwell, Oxford, 1328 pp.

Ferguson, L.E., Gibson, S.R., Opare-Obisaw, C., Ounpuu, S., Lamba, C.H. (1995): Dietary strategies for improving the zinc nutriture of rural, southern Malawian and Ghanaian children. Ecol Food Nutr, 34: 33 - 47. DOI: 10.1080/03670244.1995.9991445

Gonçalves-Neto, J.F., Alonso Toldo, M.P., Domingues Santos, C., Clóvisdo Prado Júnior, J., Fonseca, C., Albuquerque, S. (2011): Effect of zinc supplementation in pregnant mice during experimental Trypanosoma cruzi infection. Res Vet Sci, 90: 269 - 274. DOI: 10.1016/j.rvsc.2010.06.008

Hall, A., Hewitt, G., Tuffrey, V., Silva, N.D. (2008): A review and meta-analysis of the impact of intestinal worms on child growth 
and nutrition. Matern Child Nutr, 4: 118 - 123. DOI: 10.1111/j.17408709.2007.00127.x

Horáková, B., Čadková, Z., Száková, J., Jankovská, I. (2017): The identification of risk and essential elements along the strobila of the rat tapeworm Hymenolepis diminuta. J Helminthol, 91: 555 - 560. DOI: 10.1017/S0022149X16000535

Brown, K.H., Rivera, J.A., Bhutta, Z., Gibson, R.S., King, J.C., Lönnerdal, B., Ruel, M. T., Sandtröm, B., Wasantwisut, E., Hotz, C., Lopez de Romaña, D., Peerson, J.M. (2004): International Zinc Nutrition Consultative Group (IZiNCG). Technical Document No. 1. Assessment of the Risk of Zinc Deficiency in Populations and Options for Its Control. Food Nutr Bull, 25: $94-203$

House, W.A., Welch, R.M., Van Campen, D.R. (1982): Effect of phytic acid on the absorption, distribution, and endogenous excretion of zinc in rats. J Nutr, 112: 941 - 953. DOI: 10.1093/jn/112.5.941 Isaure, M.P., Huguet, S., Meyer, C.L., Castillo-Michel, H., Testemale, D., Vantelon, D., Saumitou-Laprade, P., Verbruggen, N., SarRET, G. (2015): Evidence of various mechanisms of Cd sequestration in the hyperaccumulator Arabidopsis halleri, the non-accumulator Arabidopsis lyrata, and their progenies by combined synchrotron-based techniques. J Exp Bot, 66: 3201 - 3214. DOI: 10.1093/jxb/erv131

Jackson, M.J., Jones, D.A., Edwards, R.H., Swainbank, I.G., ColeMAN, M.L. (1984): Zinc homeostasis in man: studies using a new stable isotope-dilution technique. Zinc homeostasis in man: studies using a new stable isotope-dilution technique. $\mathrm{Br} J$ Nutr, 51: 199 - 208. DOI: 10.1079/BJN19840024

Jankovská, I., SLoup, V., SzÁKovÁ, J., Langrová, I., SLoup, S. (2016): How the tapeworm Hymenolepis diminuta affects zinc and cadmium accumulation in a host fed a hyperaccumulating plant (Arabidopsis halleri). Environ. Sci. Pollut. Res., 23: 19126 - 19133. DOI: 10.1007/s11356-016-7123-1

Jankovská, l., Sloup, V., Száková, J., Magdálek, J., Nechybová, S., PeŘinková, P., LangrovÁ, I. (2018): How tapeworm infection and consumption of a $\mathrm{Cd}$ and $\mathrm{Zn}$ hyperaccumulating plant may affect $\mathrm{Cu}, \mathrm{Fe}$, and $\mathrm{Mn}$ concentrations in an animal-a plant consumer and tapeworm host. Environ. Sci. Pollut. Res., 25: 4190 - 4196. DOI: 10.1007/s11356-017-0787-3

Jensen, J., Kyvsgaard, N. CH., Battisti, A., Baptiste, K. E. (2018): Environmental and public health related risk of veterinary zinc in pig production - Using Denmark as an example. Environ Int, 114: 181 - 190. DOI: 10.1016/j.envint.2018.02.007

Jensen-Waern, M., Melin, L., Lindberg, R., Johannisson, A., PetersSON, L., Wallgren, P. (1998): Dietary zinc oxide in weaned pigs effects on performance, tissue concentrations, morphology, neu- trophil functions and faecal microflora. Res Vet Sci, 64: 225 - 231. DOI: 10.1016/S0034-5288(98)90130-8

JOHNSON, P.E. (1989): Zinc absorption and excretion in humans and animals. In Milanino R., Rainsford K.D., Velo G.P. (Eds) Copper and Zinc in Inflammation. Inflammation and Drug Therapy Series. Volume 4. Springer, Dordrecht. DOI: 10.1007/978-94-009-2619-6 Khoobbakht, Z., Roostael-Alı Mehr, M., Mohammadi, M., MohamMADGHASEMI F., MEHDI Sohan M. (2020): Supplementation of various zinc sources modify sexual development andtesticular IGF family gene expression in pre-pubertal male Japanese quail. Res Vet Sci, 130: 87 - 92. DOI: 10.1016/j.rvsc.2020.03.004

KING, J.C., Shames, D.M., Woodhouse, L.R. (2000): Zinc homeostasis in humans. J Nutr, 130: 1360 - 1366. DOI: 10.1093/ jn/130.5.1360S

KREBS, N.F. (2000): Overview of Zinc Absorption and Excretion in the Human Gastrointestinal Tract. J Nutr, 130: 1374 - 1377. DOI: 10.1093/jn/130.5.1374S

Milne, D.B., Canfield, W.K., Mahalko, J.R., Sandstead, H.H. (1984): Effect of oral folic acid supplements on zinc, copper, and iron absorption and excretion. Am J Clin Nutr, 39: 535 - 539. DOI: 10.1093/ajcn/39.4.535

PHIPPS, D.A. (1981): Chemistry and Biochemistry of Trace Metals in Biological Systems. In Lepp N.W. (Eds) Effect of Heavy Metal Pollution on Plants. Pollution Monitoring Series. Springer, Dordrecht. DOI: 10.1007/978-94-011-7339-1_1

Scott, M.E., Koskı, K.G. (2000): Zinc Deficiency Impairs Immune Responses against Parasitic Nematode Infections at Intestinal and Systemic Sites. J Nutr, 130, 1412 - 1420: DOI: 10.1093/ $\mathrm{jn} / 130.5 .1412 \mathrm{~S}$

Shengku, Y., Yiyong, Ch., Donglan, W., Xiaoyan, L., Chunzhu, L. (1994): A comparative study on the bioavailability of zinc lactate and zinc gluconate in rats. Ying Yang Xue Bao, 16: 51 - 55

Sloup, V., Jankovská, I., Száková, J., Magdálek, J., Sloup, S., LanGROVÁ, I. (2018): Effects of tapeworm infection on absorption and excretion of zinc and cadmium by experimental rats. Environ. Sci. Pollut. Res., 25: 35464 - 35470. DOI: 10.1007/s11356-018-3397-9 Sures, B., Grube, K., Taraschewski, H. (2002): Experimental Studies on the Lead Accumulation in the Cestode Hymenolepis diminuta and its Final Host, Rattus norvegicus. Ecotoxicology, 11: 365 - 368. DOI: 10.1023/A:1020561406624

WAdA, L., TURNLUND, J.R., KING, J.C. (1985): Zinc Utilization in Young Men Fed Adequate and Low Zinc Intakes. J Nutr, 110: 1345 - 1354. DOI: $10.1093 / \mathrm{jn} / 115.10 .1345$

WiLIAMS, R.J.P. (2012): Zinc in evolution. J Inorg Biochem, 111: 104 - 109. DOI: 10.1016/j.jinorgbio.2012.01.004 